\title{
Causes of hospitalization and characteristics of Algerian chronic obstructive pulmonary disease patients in Tizi-Ouzou: a retrospective study
}

\author{
Idir Ramdani ${ }^{1}$, Karen A. Pescatore ${ }^{2}$, Belaid Bouazza ${ }^{1}$ \\ ${ }^{1}$ Biochemistry and Microbiology Department, Mouloud Mammeri University of Tizi-Ouzou, Algeria; ${ }^{2}$ Department of \\ Psychology, Rowan University, Glassboro, NJ, USA
}

Correspondence: Belaid Bouazza, Biochemistry and Microbiology Department, Mouloud Mammeri University of Tizi-Ouzou, Route de Hasnaoua, 15000 Tizi-Ouzou, Algeria.

Tel. +213.561980787 .

E-mail: belaid.bouazza@ummto.dz

Key words: COPD; mortality; risk factors; epidemiology; Algeria.

Contributions: IR, collected the data, analyzed it and drafted the manuscript. KP, involved in data interpretation and manuscript drafting. $\mathrm{BB}$, was responsible for the study design, data analysis and interpretation, supervision and wrote the manuscript. All the authors have read and approved the final version of the manuscript and agreed to be accountable for all aspects of the work.

Conflict of interest: The authors declare no conflict of interest.

Ethics approval: Permission to access the medical records of the hospitalized COPD patients was authorized by the Pulmonary Care Management of the academic Belloua hospital. The study was also approved by the vice-rector services of research and postgraduates studies of the Mouloud Mammeri University of Tizi-Ouzou.

Availability of data and materials: The medical records including the patient's history, diagnosis, and list of medications are contained in a file and maintained by the specialist. The file code, the patient's name, the hospitalization cause and the admission and discharge dates are contained in the hospitalization register regularly maintained by the medical assistant. The medical records files are kept in the archives room.

Patient consent for publication: Not applicable.

Acknowledgments: We would like to thank Dr Chahed R., pulmonologist (Tizi-Ouzou) for critically reading the manuscript, Ms. Aba M., Ms. Bourane L., for helping with data collection and the medical staff of the pulmonology service at the Belloua hospital for technical assistance.

Conference presentation: This study was accepted as a poster presentation at ATS-2020 (D57-Population based studies on COPD, \#11955), May 15-20, 2020, Philadelphia, USA.

Received for publication: 15 April 2020.

Accepted for publication: 6 May 2020.

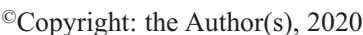

Licensee PAGEPress, Italy

Monaldi Archives for Chest Disease 2020; 90:1317

doi: 10.4081/monaldi.2020.1317

This article is distributed under the terms of the Creative Commons Attribution Noncommercial License (by-nc 4.0) which permits any noncommercial use, distribution, and reproduction in any medium, provided the original author(s) and source are credited.

\begin{abstract}
Chronic obstructive pulmonary disease (COPD) is a progressive chronic inflammatory disease and the third cause of death worldwide in 2016. COPD epidemiology is well documented in high-income countries where the disease is well managed. However, the disease is neglected in low-income countries and there is lack of data. Our study aims to identify COPD patients' characteristics and hospital admission causes, and to determine disease etiologies and associated factors. A retrospective study was conducted in COPD Algerian patients using medical record data collected from January 2007 to May 2017 at the pulmonology department of the Belloua Hospital of Tizi-Ouzou city. Out of 133 hospital admissions for COPD during the study period, only 120 records were found and analyzed. Most of the admitted patients were men (96\%) and the mean age was $74.29 \pm 9.56$ years. Among them, $78.7 \%$ were in the GOLD stage III or IV and 9 deaths $(7.5 \%)$ were recorded during the study period. Interestingly, disease severity is associated with increasing age of the patients and mortality ( $\mathrm{p}=0.01$ and $\mathrm{p}=0.02$, respectively). Risk factors include cigarette smoking $(93 \%)$, history of medical conditions $(36.66 \%)$ with the most prevalent conditions being emphysema (38.63\%) and asthma (27.27\%), the cold season (47\%), and occupational exposures (58\%). Most of the admissions (64.16\%) were due to acute dyspnea and $21.66 \%$ to respiratory infections, however, $34.16 \%$ of patients were readmitted at least one time. Comorbidities were observed in $57.5 \%$ of the patients, including cardiovascular diseases $(63.76 \%)$ and diabetes $(18.84 \%)$. These results show that COPD severity is associated with age and mortality. Better understanding of the COPD etiologies and the causes of hospital admission will lead to more effective management of the disease.
\end{abstract}

\section{Introduction}

COPD is a common disease characterized by airway limitation usually progressive and partially reversible caused by airway and/or alveolar abnormalities produced by significant exposure to noxious particles or gases [1]. Its prevalence has been increasing worldwide for 20 years, reaching 251 million cases in 2016 [2]. COPD caused up to 3 million deaths in 2016, and currently represents the third cause of death in the world [3]. In Algeria, a study carried out in 2009 showed that the prevalence of COPD was $4.9 \%$ in general population, it remains rare in the young population $(0.1 \%)$ but reaches $9.2 \%$ in the older population (> 40 years) [4]. 
COPD is due to a complex interaction of internal and external factors. The main risk factors associated with COPD are:

- Cigarette smoking, which represents the main cause of the disease. Indeed, $50 \%$ of smokers develop obstructive ventilatory disorders, and 10 to $20 \%$ develop a COPD [5].

- Other environmental factors, such as internal and external air pollution and occupational exposure were reported to increase the risk of developing COPD [6].

- Genetic factors, such as severe deficiency of $\alpha-1$ antitrypsin [7], and matrix metalloproteinase and glutathione S-transferase gene polymorphisms affect the occurrence of COPD [8].

COPD epidemiology is poorly documented in Africa, particularly in Algeria. In this study, we aimed to determine the characteristics of COPD patients hospitalized for exacerbation (frequently for dyspnea and respiratory infections) in the Belloua academic hospital of Tizi-Ouzou city, and to identify the main risk factors associated with COPD.

\section{Methods}

This was a retrospective longitudinal observational study of series-cases of COPD patients hospitalized from January 2007 to May 2017 in Pulmonology service of the Belloua hospital in TiziOuzou city (Algeria). Tizi-ouzou is one of the Kabyle cities located in the north of Algeria with a socioeconomic diverse population of approximately $1,127,165$ people according to the last population census [9]. The pulmonary care service of the Belloua hospital is subdivided into four units, including medical consultations unit, exploration unit, men hospitalization unit (33 beds) and women hospitalization unit (also 33 beds), operated by a team of six doctors (pulmonologists, allergists).

The medical records including the patient's history, diagnosis, and list of medications are contained in a file and maintained by the specialist. The file code, the patient's name, the hospitalization cause and the admission and discharge dates were contained in the hospitalization register regularly maintained by the medical assistant. The medical records files were kept in the archives room.

All COPD patients hospitalized during the study period and diagnosed by a specialist were included. COPD diagnosis was determined by a systemic clinico-radiological screening. Spirometry after post-bronchodilator was done for half of the admitted patients. Tuberculosis (TB) was diagnosed after symptoms and imaging analysis (chest X-ray, tuberculin skin test); however, TB confirmation was later performed by sputum microscopic analysis and culture at the Pasteur Institute of Algiers. Acute dyspnea and respiratory infections were investigated in different services (Blood Tests Lab, Microbiology Lab, Radiology, etc.) at the academic Belloua hospital. Indeed, blood count, C-reactive protein, oximetry and chest X-ray were performed systemically, however, electrocardiogram (ECG), arterial blood gas and microscopic and sputum culture were performed according to the patient health status and the disease signs.

Hospitalized patients are directed either from the Pulmonary Consultation Unit or from the Emergency Department. Data about demographic characteristics, smoking status, readmissions, stage of the disease, medical history, comorbidities, and causes of admission and death, were collected and analyzed. Moreover, we noted the period of hospitalization to assess the effect of seasonal variations on COPD.

Permission to access the medical records of the hospitalized COPD patients was authorized by the Pulmonary Care
Management of the academic Belloua hospital. The study was also approved by the vice-rector services of research and postgraduates studies of the Mouloud Mammeri University of Tizi-Ouzou.

\section{Statistical analysis}

Quantitative data were analyzed with Microsoft Excel (mean and SD) and Statistica software. The Pearson's chi-squared test $\left(\chi^{2}\right)$ was used to assess differences between categorical variables, and a $\mathrm{P}<0.05$ was considered statistically significant.

\section{Results}

\section{Patients' demographic and clinical characteristics}

Out of the 133 COPD patients admitted to the pulmonology services of the Belloua hospital for different causes, only 120 medical records were found and analyzed: 13 patients hospitalized during 2016-2017 who also had other health issues were transferred with their medical files to other health services (cardiology, oncology, surgery, etc.). More than $95 \%$ of patients were men. The mean age was $74.29 \pm 9.56$. Most of the patients $(n=113,94 \%)$ were aged $\geq 60$ and they were living in an urban area (61.66\%) (Table 1).

The yearly admission rate was $12.09 \pm 3.75$. The highest number of admissions was observed in 2007 (19 admissions), while the lowest rate was recorded in 2008 (8 admissions). Most of the patients were in the GOLD stage III or IV of the disease $(34.42 \%$ and $44.26 \%$, respectively). The mean $\%$ FEV1 post-bronchodilator was 65.2 in the GOLD I/II and 34.2 in GOLD III/IV. Twentysix $(21.66 \%)$ patients were admitted with acute respiratory failure (ARF) and for some of them with hypercapnia (9), non-invasive ventilation was prescribed. Eight $(6.7 \%)$ patients were on longterm oxygen therapy. Interestingly, the disease severity was found to be dependent on the age of patients $(p=0.01)$. However, GOLD classification was available only for half of the patients and needed to be applied to all admitted patients.

\section{Risk factors}

Cigarette smoking was the main COPD risk factor found in this study. Indeed, $92.5 \%$ of patients were smokers or former smokers. Among them, $71.17 \%$ smoked more than 50 packs of cigarettes/year, but most of them (81.98\%) had quit smoking (Table $1)$. However, the $\chi^{2}$ test shows no relationship either between cigarette smoking $(\mathrm{p}=0.91)$, or between smoking cessation $(\mathrm{p}=0.15)$, and the stage of the disease. The lack of statistical significance could be due to the lack of information about smoking duration as well as the length of time between quitting smoking and diagnosis. However, in women, second hand smoking and biomass exposure were found to be the main risk factors for COPD onset and hospitalization (data not shown), although for review see [10].

Medical history of related lung diseases was clinically significant. In fact, $36.66 \%(n=44)$ of the patients have a medical condition associated with COPD. Specifically, 38.63\% $(n=17)$ have centrilobular emphysema, $27.27 \%(n=12)$ have bronchial asthma, $15.9 \%(\mathrm{n}=7)$ have chronic bronchitis and $18.18 \%(\mathrm{n}=8)$ have tuberculosis (Table 2).

Other risk factors found in the study include alcohol consumption (46\%), chewing tobacco (14\%), occupational exposure (73.33\%), and catching cold (47\%). 
Table 1. Demographic and clinical characteristics of COPD patients.

\begin{tabular}{|c|c|}
\hline Characteristics & \# Patients (\%) \\
\hline $\begin{array}{l}\text { Sex } \\
\text { - Male } \\
\text { - Female }\end{array}$ & $\begin{array}{l}115(95.83) \\
5(4.16)\end{array}$ \\
\hline $\begin{array}{l}\text { Age (years) } \\
-50-70 \\
-\quad 70-90 \\
-\quad 90-100 \\
\end{array}$ & $\begin{array}{l}41(34.16) \\
72(60) \\
7(5.83)\end{array}$ \\
\hline $\begin{array}{l}\text { Disease stage } \\
\text { - } \quad \text { Stage I }(\mathrm{FEV1} \geq 80 \%) \\
\text { - } \quad \text { Stage II }(50 \% \leq \mathrm{FEVl}<80 \%) \\
\text { - } \quad \text { Stage III }(30 \% \leq \mathrm{FEVl}<50 \%) \\
\text { - } \quad \text { Stage IV }(\mathrm{FEV1}<30 \%)\end{array}$ & $\begin{array}{c}2(3.27) \\
11(18.03) \\
21(34.42) \\
27(44.26)\end{array}$ \\
\hline $\begin{array}{l}\text { Habitat } \\
\text { - Urban area } \\
\text { - } \text { Rural area }\end{array}$ & $\begin{array}{l}74(61.66) \\
46(38.33)\end{array}$ \\
\hline $\begin{array}{l}\text { Tobacco } \\
\text { - Smokers } \\
\text { - } \text { Former smokers } \\
\text { - } \text { Current smokers } \\
\text { - } \text { Never smokers }\end{array}$ & $\begin{array}{l}111(92.5) \\
91(81.98) \\
20(18.01) \\
9(7.5)\end{array}$ \\
\hline $\begin{array}{l}\text { Cigarette packs/year } \\
-\quad 0-20 \\
-\quad 21-50 \\
-\quad \geq 51\end{array}$ & $\begin{array}{c}9(8.1) \\
23(20.72) \\
79(71.17)\end{array}$ \\
\hline Chewing tobacco & $17(14.16)$ \\
\hline $\begin{array}{l}\text { Alcohol } \\
\text { - Consumer } \\
\text { - Non-consumer } \\
\text { - Not informed }\end{array}$ & $\begin{array}{l}49(40.83) \\
55(45.83) \\
16(13.33)\end{array}$ \\
\hline $\begin{array}{l}\text { Hospitalizations } \\
\text { - Once } \\
->1 \\
\text { - Not informed }\end{array}$ & $\begin{aligned} & \\
& 75(62.5) \\
& 41(34.16) \\
& 4(3.33)\end{aligned}$ \\
\hline $\begin{array}{l}\text { Readmission (R) } \\
\text { - Once } \\
\text { - Twice } \\
\text { - } 2>R \leq 12\end{array}$ & $\begin{array}{l}19(46.34) \\
08(19.51) \\
14(34.14)\end{array}$ \\
\hline $\begin{array}{l}\text { ARF at admission } \\
\text { Long term oxygen therapy }\end{array}$ & $\begin{array}{c}26(21.66) \\
8(6.7)\end{array}$ \\
\hline $\begin{array}{l}\text { Motive of hospital admission } \\
\text { - Dyspnea } \\
\text { - Infections } \\
\text { - Respiratory infections } \\
\text { - Problem with treatment } \\
\text { - Decompensation (severe exacerbation) } \\
\text { - Chest pain } \\
\text { - Pneumothorax } \\
\text { - Tumor } \\
\text { - Chronic pulmonary heart disease } \\
\text { - Other }\end{array}$ & $\begin{array}{c}77(64.16) \\
39(32.5) \\
26(21.66) \\
4(3.33) \\
4(3.33) \\
3(2.5) \\
2(1.66) \\
2(1.66) \\
2(1.66) \\
5(4.16)\end{array}$ \\
\hline $\begin{array}{l}\text { Season of admission } \\
\text { - } \quad \text { Cold season (December-March) } \\
\text { - Hot season (June-September) } \\
\text { - } \quad \text { Other }\end{array}$ & $\begin{array}{c}62(51.66) \\
36(30) \\
22(18.33)\end{array}$ \\
\hline $\begin{array}{l}\text { Occupational exposure } \\
\text { - High risk } \\
\text { - Low risk }\end{array}$ & $\begin{array}{l}88(73.33) \\
32(26.66)\end{array}$ \\
\hline
\end{tabular}

FEV1, forced expiratory volume in one second; ARF, acute respiratory failure.

\section{Hospital admission, comorbidities and mortality}

Out of the 120 patients, 75 (62.5\%) were admitted one time, 41 $(34.16 \%)$ were admitted more than one time, and 4 (3.3\%) had no data about number of admissions. Interestingly, more than half of the readmitted patients $(53.65 \%)$ had two or more readmissions during the study period (Table 1). Most of the hospitalizations were due to acute dyspnea $(64.16 \%)$ and to respiratory infections $(21.66 \%)$ (Table 1). Comorbidities were present in 69 patients $(57.5 \%)$, including cardiovascular diseases $(n=44,63.76 \%)$, diabetes $(n=13,18.84 \%)$, inguinal hernia $(n=10,14.49 \%)$, lung opacities and cancer $(n=10,14.5 \%)$.

COPD may worsen and be fatal: 9 deaths $(7.5 \%)$ were recorded among the 120 patients admitted during the study period (10 years) and approximately one death per year was registered $(0.82 \pm 0.83)$. As expected, the $\mathrm{c}^{2}$ test shows that the death risk was related to the severity of the disease $(\mathrm{P}=0.02)$.

\section{Discussion}

COPD is one of the most prevalent diseases and is considered to be the third leading cause of deaths in the world [3]. In this study, we investigated the hospitalization motive, mortality, and the main risk factors associated to COPD in the academic hospital of Tizi-Ouzou city, Algeria. To our knowledge, this is the first retrospective study investigating COPD etiology and hospitalization in Algeria. Indeed, there is lack of data about COPD in Africa and particularly in Algeria. Hence, it is difficult to manage disease progression and its impact on the population's health.

During the study period, there were 133 COPD patients admitted in the Belloua hospital. However, data were collected from only 120 medical records found. Our study revealed that the majority of hospitalizations were subsequent to emergency room admission and all admissions required at least a night of hospitalization. Death ratio was important among hospitalized patients; in fact, almost one death per year was recorded during the study period (one death/11 hospitalizations). However, COPD seems to be underestimated in Algeria, indeed, only one study has investigated the prevalence of COPD and reported a prevalence of $4.9 \%$ in the country's general population [4].

The readmission rate is an important indicator to assess the quality of care and to evaluate the disease control in COPD patients. In this study, the rate of readmission was $34.16 \%$. About half of these patients $(46.34 \%)$ were readmitted once, $19.51 \%$ were readmitted twice and $34.14 \%$ were readmitted three or more times. Unexpectedly, some patients had a maximum of 12 readmissions. The main causes of hospitalization were acute dyspnea $(64.16 \%)$, followed by respiratory infections $(21.66 \%)$; this finding may indicate poor and ineffective management of the disease.

Table 2. Medical history of COPD components and related lung diseases.

\begin{tabular}{lc} 
COPD phenotypes and related disease & $\mathrm{n}=44$ patients (\%) \\
Centrilobular emphysema & $17(38.63)$ \\
Bronchial asthma & $12(27.27)$ \\
\hline Chronic bronchitis & $7(15.9)$ \\
Tuberculosis & $8(18.18)$ \\
\hline
\end{tabular}


Most of the admitted patients (95.83\%) were men and only $4.16 \%$ were women, which is in accordance with the high rate of smokers $(92.5 \%)$ among patients. Specifically, most of smokers in Algeria are men [11], and cigarette smoking is the most important risk factor for developing COPD. The same trends were observed in other countries, including Tunisia, where $49.4 \%$ of men and $7.3 \%$ of women smoke, the prevalence of COPD was $13.5 \%$ in men and $1.9 \%$ in women [12]; and Morocco where $40.3 \%$ of men and only $0.6 \%$ of women smoke, the prevalence of COPD was $16.6 \%$ in men and $8.3 \%$ in women. In addition, COPD is underdiagnosed in women compared to men [13], indeed, men are more likely to be directed to a pulmonologist or have spirometry testing than women [14].

Conversely, we found that almost $82 \%$ of smokers had stopped smoking. It is well known that smoking status has a major role in both COPD onset and its development or progression. Indeed, smoking cessation can be a measure to prevent COPD in healthy persons [15], and may reduce exacerbations, slow disease progression, and reduce the mortality rate in patients with COPD [16]. However, smoking duration is unknown in our study. In fact, some of the patients did not remember precisely when they quit smoking and some may consider themselves as non-smokers when they smoke occasionally. In addition, it may be that healthcare specialists, perhaps due to brevity, have a tendency to mention the smoking status of the patient (smoker, former smoker, etc.) instead of reporting the date of initiating smoking and/or the date of quitting.

Alcohol and chewing tobacco are possible risks for COPD onset and exacerbation [17,18]. However, alcohol consumption and chewing tobacco effects on COPD are not clear and more investigations are needed to confirm their association to disease development and progression.

Most of patients $(94.17 \%)$ were aged $\geq 60$ years and almost all of them $(78.7 \%)$ were in stage III or IV of disease progression according to the GOLD criteria for COPD severity [1]. Indeed, GOLD severity was reported to predict hospital admissions for exacerbation [19]. Interestingly, age is significantly associated with the disease severity $(\mathrm{p}=0.01)$. In fact, COPD is a progressive and age related disease. Elderly COPD patients are characterized by muscle weakness and age related comorbidities. Indeed, it was reported that with age, symptoms increase and forced expiratory volume in one second decrease, which may lead to more exacerbations and hospitalizations [20]. Unexpectedly, less than $22 \%$ of the admitted patients were in GOLD stage I/II and were hospitalized for different reasons including chest pain, cancer, decompensation, heart disease, dyspnea and infections. This reinforces the fact that those in these GOLD classes are vulnerable and at risk of exacerbation and death despite having better spirometry [21]. Another interesting study, reported a shift from the 2007 1-4 GOLD classification to the 2011 A-D classification. In a population-based study, they found that the new classification resulted in more individuals belonging to the most severe group (GOLD D), in the 2011 update $(n=295)$ in comparison with only 45 individuals belonging to the most severe group (GOLD 4), in the 2007 classification. It was concluded that the new GOLD classification A-D provides better diagnostic in predicting exacerbations than the GOLD 2007 1-4 stratification [22].

However, the GOLD classification was limited to only half of the patients admitted during the study period. In some cases, spirometry was not performed because of the health status of the admitted patient. Indeed, spirometry may be difficult to perform during an exacerbation. On the other hand, in developing countries including Algeria, patient access to the lung function laboratories is limited and/or COPD diagnosis was determined independently of spirometry. In addition, it was reported that also in Africa, there is a limited availability of equipment, lack of human and financial resources and poor access to training and skilled technicians [23]. In fact, the underuse of spirometry was not limited to developing countries but also to developed countries including Italy [24], Belgium, USA, and Sweden [25]. As a consequence, classifying COPD patients using the new GOLD standards should be recommended for each patient in order to identify patients at high risk to better target patient care.

$\mathrm{ARF}$ is one of the complications of COPD progression. In this study, we found that 26 patients $(21.66 \%)$ were admitted with acute respiratory failure, among them nine were with hypercapnia. COPD exacerbation may lead to ARF and hospitalization. In fact, COPD was reported to be a major risk factor for ARF [26]. Indeed, $3 \%$ of COPD patients had experienced at least one episode of ARF during a five year follow-up study, which represents $12 \%$ of hospitalizations [27]. Moreover, ARF was found to be associated with an increasing mortality rate in COPD patients after three years following hospitalization [28]. In our study, we found that mortality is related to the disease severity; however, it is of importance to investigate the mortality rate of COPD patients who had ARF after hospital discharge.

Evaluating medical history and symptoms is an effective way to diagnose COPD-related lung diseases and comorbidities. Our results showed that more than $36 \%$ of COPD patients had a history of a medical condition related to the disease (Table 2). Emphysema and bronchial asthma were the most prevalent (38.63\% and $27.27 \%$, respectively), followed by tuberculosis $(18.18 \%)$, and chronic bronchitis $(15.9 \%)$. The coexistence of COPD and bronchial asthma is an independent risk factor for more exacerbations per year compared to COPD alone [29]. Indeed, patients can present symptoms of both diseases, but the distinction between these is not possible using physiological tests [30], this coexistence is known as asthma-COPD overlap syndrome, and it affect a quarter of patients with COPD [31]. History of tuberculosis is related to more prevalence of COPD, more exacerbations, earlier diagnosis of COPD and earlier deaths compared to controls without tuberculosis history [32]. However, emphysema and chronic bronchitis are phenotypic components of COPD [33]. The former may lead to lung tissue destruction and life quality impairment [34], while the latter is associated with worsening lung function and increased risk for exacerbation [35] in COPD patients.

Cardiovascular disease was one of the greatest factors contributing to comorbidity in this study (Table 3 ). It is one of the

Table 3. Comorbidities associated with COPD.

\begin{tabular}{ll} 
Comorbidities & $\mathrm{n}=69$ patients* $(\%)$ \\
Cardiovascular disease & $44(63.76)$ \\
Diabetes & $13(18.84)$ \\
\hline Inguinal hernia & $10(14.49)$ \\
Lung opacities & $07(10.14)$ \\
\hline Kidney disease & $06(08.69)$ \\
Prostate damage & $05(07.24)$ \\
\hline Bronchiectasis & $04(05.79)$ \\
Tumors & $03(04.34)$ \\
\hline Pneumothorax & $02(02.89)$
\end{tabular}

*One patient may have more than one comorbidity. 
important comorbidities in COPD [36], and was reported to be linked to an increased length of stay in hospital, higher risk for intensive care unit, and higher risk of death [37]. Additionally, more than $18 \%$ of COPD patients have diabetes. This comorbidity is associated with a high rate of pro-inflammatory molecules such as interleukin 6 and C-reactive protein which may affect the lungs [38]. Other comorbidities found in our study include inguinal hernia $(14.49 \%)$, kidney disease $(8.69 \%)$ and prostate damage (7.24\%), which may be important in COPD morbidity and mortality as these diseases are linked to age. However, further investigation is needed to clarify the role of these diseases in COPD development and progression.

It is known that occupational exposure to dust, fumes and gases may contribute to developing COPD. In this study, we found that more than $73 \%$ of COPD patients had an occupation with high-COPD risk. Most of the patients are highly exposed to different particles in their job. Many studies showed a correlation between occupational exposure and COPD. According to Peiffer et al. [39], 15 to $20 \%$ of COPD cases are due to occupational exposure, indeed, many jobs are related to increase the risk of COPD [40]. On the other hand, particle exposure is related to lung function impairment and increasing COPD symptoms [41]. Additionally, the common cold was reported as a risk factor for COPD exacerbation [42]. In fact, we noticed that almost half $(47 \%)$ of the admissions occurred during the cold season. It was reported that COPD exacerbation frequency increases with the common cold [43]. A study in Porto showed that the duration of the cold season and therefore how long one might be exposed to acquiring the common cold, is more significant than very low temperatures in contributing to COPD exacerbations, which explains the increase of admissions in cold season and not in episodic falling in temperature [44]. The same result was found in the United States where it appears that disease exacerbations are increased in winter and are associated with increased morbidity and mortality [45]. However, the underlying molecular mechanism is still not well understood. In addition, cold induces an increase in airway infections [46], which is an important risk factor for COPD exacerbation [47].

In 10 years, nine deaths due to COPD were recorded, this represents a $7.5 \%$ mortality rate, a result similar to that reported by others [48]. Mortality was significantly $(p<0.05)$ associated with the disease severity. Indeed, the risk of death was reported to be proportional to the disease severity [49], this is probably due to a low score in forced expiratory volume in one second in patients with severe COPD, which is associated to high level of mortality [50].

Our study presents some limitations, as do retrospective studies. Some data were missing (Alpha-1 antitrypsin deficiency screening and smoking duration) and some were not available for all patients (incomplete records, GOLD classification, comorbidities and medical history). However, despite these limitations, this is the first retrospective longitudinal study to report COPD etiology and causes of hospital admission in the COPD Algerian population.

In conclusion, our study highlighted the main risk factors associated with COPD, and the most common causes of hospital admissions in the academic hospital in Tizi-Ouzou city. We concluded that COPD severity is related to increasing age of patients and to mortality. Our results suggest that a better understanding of disease etiology, causes of exacerbation of disease symptoms and hospital admissions, may help to improve patient/disease management, and as a consequence, this may reduce hospitalization frequency and improve quality of life of COPD patients.

\section{References}

1. Global Initiative for Chronic Obstructive Lung Disease GOLD. Gold Reports for Personal Use. 2019. Available from: https://goldcopd.org/gold-reports/

2. WHO. Bronchopneumopathie chronique obstructive (BPCO). Available from: https:/www.who.int/fr/news-room/factsheets/detail/chronic-obstructive-pulmonary-disease-(copd)

3. WHO. Top 10 causes of death. [cited 2019 Nov 27]. Available from: http://www.who.int/gho/mortality_burden_disease/causes_death/top_10/en/

4. Khelafi R, Aissanou A, Tarsift S, Skander F. [Epidemiology of chronic obstructive pulmonary disease in Algiers]. Rev Mal Respir 2011;28:32-40.

5. Devereux G. ABC of chronic obstructive pulmonary disease. Definition, epidemiology, and risk factors. BMJ 2006; 332:1142-4.

6. Postma DS, Bush A, van den Berge M. Risk factors and early origins of chronic obstructive pulmonary disease. Lancet Lond Engl 2015;385:899-909.

7. Greene CM, Marciniak SJ, Teckman J, et al. $\alpha 1$-Antitrypsin deficiency. Nat Rev Dis Primer 2016;2:16051.

8. Stankovic M, Nikolic A, Nagorni-Obradovic L, et al. GeneGene interactions between glutathione S-transferase M1 and matrix metalloproteinases 1,9 , and 12 in chronic obstructive pulmonary disease in Serbians. COPD 2017;14:581-9.

9. APW Tizi-Ouzou. Evolution intercensitaire de la population. Site Off. Wilaya Tizi-Ouzou [cited 2020 Apr 10]. Available from: http://wilaya-tiziouzou.dz/evolution-intercensitaire-dela-population

10. Capistrano SJ, van Reyk D, Chen H, Oliver BG. Evidence of biomass smoke exposure as a causative factor for the development of COPD. Toxics 2017;5.

11. WHO. Report on the global tobacco epidemic, 2019. Country Profile: Algeria 2019.

12. Daldoul H, Denguezli M, Jithoo A, et al. Prevalence of COPD and tobacco smoking in Tunisia - Results from the BOLD Study. Int J Environ Res Public Health 2013;10:7257-71.

13. Ancochea J, Miravitlles M, García-Río F, et al. Underdiagnosis of chronic obstructive pulmonary disease in women: quantification of the problem, determinants and proposed actions. Arch Bronconeumol 2013;49:223-9.

14. Aryal S, Diaz-Guzman E, Mannino DM. Influence of sex on chronic obstructive pulmonary disease risk and treatment outcomes. Int J Chron Obstruct Pulmon Dis 2014;9:1145-54.

15. Bhatt SP, Kim Y, Harrington KF, et al. Smoking duration alone provides stronger risk estimates of chronic obstructive pulmonary disease than pack-years. Thorax 2018;73:414-21.

16. Au DH, Bryson CL, Chien JW, et al. The effects of smoking cessation on the risk of chronic obstructive pulmonary disease exacerbations. J Gen Intern Med 2009;24:457-63.

17. Schivo M, Avdalovic MV, Murin S. Non-cigarette tobacco and the lung. Clin Rev Allergy Immunol 2014;46:34-53.

18. Kaluza J, Harris HR, Linden A, Wolk A. Alcohol Consumption and risk of chronic obstructive pulmonary disease: A prospective cohort study of men. Am. J. Epidemiol. 2019;188:907-16.

19. Lusuardi M, Lucioni C, De Benedetto F, et al. GOLD severity stratification and risk of hospitalisation for COPD exacerbations. Monaldi Arch Chest Dis 2008;69:164-9.

20. Barnes PJ, Burney PGJ, Silverman EK, et al. Chronic obstructive pulmonary disease. Nat Rev Dis Primer 2015;1:15076. 
21. Dusser D, Wise R, Dahl R, et al. Differences in outcomes between GOLD groups in patients with COPD in the TIOSPIR\&reg trial. Int $\mathrm{J}$ Chron Obstruct Pulmon Dis 2016;133.

22. Lange P, Marott JL, Vestbo J, et al. Prediction of the clinical course of chronic obstructive pulmonary disease, using the new GOLD classification: A study of the general population. Am. J. Respir. Crit. Care Med. 2012;186:975-81.

23. Masekela R, Zurba L, Gray D. Dealing with access to spirometry in Africa: A commentary on challenges and solutions. Int J Environ Res Public Health 2018;16:62.

24. Caramori G, Bettoncelli G, Tosatto R, et al. Underuse of spirometry by general practitioners for the diagnosis of COPD in Italy. Monaldi Arch. Chest Dis 2005;63:651.

25. Roberts NJ, Smith SF, Partridge MR. Why is spirometry underused in the diagnosis of the breathless patient: a qualitative study. BMC Pulm Med 2011;11:37.

26. Gadre SK, Duggal A, Mireles-Cabodevila E, et al. Acute respiratory failure requiring mechanical ventilation in severe chronic obstructive pulmonary disease (COPD). Medicine (Baltimore) 2018;97:e0487.

27. Chung W-S, Lin C-L. Acute respiratory events in patients with bronchiectasis-COPD overlap syndrome: A population-based cohort study. Respir Med 2018;140:6-10.

28. Perrin C, Vandenbos F, Tamisier R, et al. [Impact of acute respiratory failure on survival of COPD patients managed with long-term non-invasive ventilation and oxygen therapy]. Rev Mal Respir 2000;17:91-7.

29. Lee H, Rhee CK, Lee B-J, et al. Impacts of coexisting bronchial asthma on severe exacerbations in mild-to-moderate COPD: results from a national database. Int J Chron Obstruct Pulmon Dis 2016;11:775-83.

30. Hillas G, Tzanakis N, Perlikos F, Tsiligianni I. Managing comorbidities in COPD. Int $\mathrm{J}$ Chron Obstruct Pulmon Dis 2015;10:95-109.

31. Alshabanat A, Zafari Z, Albanyan O, et al. Asthma and COPD overlap syndrome (ACOS): A systematic review and meta analysis. PloS One 2015;10:e0136065.

32. North CM, Allen JG, Okello S, et al. HIV infection, pulmonary tuberculosis, and COPD in rural Uganda: A cross-sectional study. Lung 2018;196:49-57.

33. Corlateanu A, Mendez Y, Wang Y, et al. Chronic obstructive pulmonary disease and phenotypes: a state-of-the-art. Pulmonology 2020;26:95-100.

34. Schleich F, Louis R. It needs more than just eosinophils to cause emphysema in COPD. Eur Respir J 2019;53:1900332.

35. Kim V, Criner GJ. Chronic bronchitis and chronic obstructive pulmonary disease. Am J Respir Crit Care Med 2013;187: 228-37.

36. Kinnunen T, Säynäjäkangas O, Keistinen T. Features of hospi- talisations for acute exacerbation of COPD resulting in death. Monaldi Arch Chest Dis 2016;67:504.

37. Aliyali M, Mehravaran H, Abedi S, et al. Impact of comorbid ischemic heart disease on short-term outcomes of patients hospitalized for acute exacerbations of COPD. Tanaffos 2015; 14:165-71.

38. Cazzola M, Rogliani P, Calzetta L, et al. Targeting mechanisms linking COPD to type 2 diabetes mellitus. Trends Pharmacol Sci 2017;38:940-51.

39. Peiffer G, Underner M, Perriot J, Dalphin J-C. [COPD: think about occupational exposures!].[Article in French]. Rev Prat 2018;68:74-8.

40. Lytras T, Kogevinas M, Kromhout H, et al. Occupational exposures and 20-year incidence of COPD: the European Community Respiratory Health Survey. Thorax 2018;73: 1008-15.

41. Javed H, Ghani N, Ghani N, Fatima A. Occupational health surveillance: pulmonary function testing and oxidative stress among photocopying workers in Pakistan. Med Pr 2019;70: 403-10.

42. Johnston N, Olsson M, Edsbäcker S, et al. Colds as predictors of the onset and severity of COPD exacerbations. Int J Chron Obstruct Pulmon Dis 2017;12:839-48.

43. Hurst JR, Donaldson GC, Wilkinson TMA, et al. Epidemiological relationships between the common cold and exacerbation frequency in COPD. Eur Respir J 2005;26:846-52.

44. Monteiro A, Carvalho V, Góis J, Sousa C. Use of "Cold Spell" indices to quantify excess chronic obstructive pulmonary disease (COPD) morbidity during winter (November to March 2000-2007): case study in Porto. Int J Biometeorol 2013;57: $857-70$.

45. Donaldson GC, Wedzicha JA. The causes and consequences of seasonal variation in COPD exacerbations. Int $\mathrm{J}$ Chron Obstruct Pulmon Dis 2014;9:1101-10.

46. Ikäheimo TM, Jaakkola K, Jokelainen J, et al. A decrease in temperature and humidity precedes human rhinovirus infections in a cold climate. Viruses 2016;8:244.

47. Moghoofei M, Azimzadeh Jamalkandi S, Moein M, et al. Bacterial infections in acute exacerbation of chronic obstructive pulmonary disease: a systematic review and meta-analysis. Infection 2020;48:19-35.

48. Molinari N, Briand C, Vachier I, et al. Hospitalizations for COPD exacerbations: Trends and determinants of death. COPD 2015;12:621-7.

49. Mattila T, Vasankari T, Kanervisto M, et al. Association between all-cause and cause-specific mortality and the GOLD stages 1-4: A 30-year follow-up among Finnish adults. Respir Med 2015;109:1012-8.

50. Berry CE, Wise RA. Mortality in COPD: Causes, risk factors, and prevention. COPD 2010;7:375-82. 